\title{
A novel technique of annular ligament reconstruction using extensor carpi radialis longus tendon fascia: a report of 3 cases
}

\author{
Adit Maniar ${ }^{1 *}$, Sagar Kakatkar² \\ ${ }^{1}$ Department of Orthopaedics, Ark Hospital, Mumbai, Maharashtra, India \\ ${ }^{2}$ Department of Orthopaedics, Sahyadri Hospitals, Nashik, Maharashtra, India
}

Received: 01 February 2021

Accepted: 04 March 2021

\author{
*Correspondence: \\ Dr. Adit Maniar, \\ E-mail: aditmaniar@gmail.com
}

Copyright: (c) the author(s), publisher and licensee Medip Academy. This is an open-access article distributed under the terms of the Creative Commons Attribution Non-Commercial License, which permits unrestricted non-commercial use, distribution, and reproduction in any medium, provided the original work is properly cited.

\begin{abstract}
Annular ligament is an important stabiliser of radial head. In cases of chronic radial head dislocation, annular ligament reconstruction is warranted to maintain radial head reduction to improve elbow function. We have reported here a novel technique using the fascia overlying extensor carpi radialis longus tendon for annular ligament reconstruction. We reported an average flexion of $130^{\circ}$ and full supination in all 3 cases. 2 patients achieved mid pronation and 1 achieved full pronation; comparable with other described techniques. Our novel technique through a single incision has excellent functional outcomes. Additionally, it is simple, cost effective, requires no hardware.
\end{abstract}

Keywords: Annular ligament, Chronic radial head dislocation, Reconstruction, Extensor carpi radialis longus, Neglected

\section{INTRODUCTION}

Radial head articulates with the capitellum of humerus and ulna forming the radio capitellar joint and proximal radioulnar joint respectively. Dislocation of radial head reduces movements of the elbow and proximal radio-ulnar joint hampering both flexion-extension and pronationsupination. Chronic radial head dislocation is seen either post traumatic or as a congenital condition. To re-establish elbow movements, reduction of the radial head and its maintenance is very important. Chronic radial head dislocation is usually associated with damage to the annular ligament. This ligament is a strong band of fibers, which encircles the head of the radius, and retains it in contact with the radial notch of the ulna. It forms about four-fifths of the osseo-fibrous ring, and is attached to the anterior and posterior margins of the radial notch; a few of its lower fibers are continued around below the cavity and form at this level a complete fibrous ring. Its upper border blends with the anterior and posterior ligaments of the elbow, while from its lower border, a thin loose membrane passes to be attached to the neck of the radius. ${ }^{1}$ Annular ligament limits forward, backward and lateral displacement of the radial head. ${ }^{2}$ It plays an important role in posterolateral stability of the elbow. ${ }^{3,4}$ Søjbjerg et al found that annular ligament is the prime stabiliser of the lateral aspect of the elbow. They also stated that the stability of the elbow joint can be improved post radial head resection by properly preserving the annular ligament. ${ }^{5}$ Traditionally, radial head excision has been the choice of treatment for chronic radial head dislocations. Though it provides substantial pain relief, excision is associated with only modest improvement in forearm rotation and no improvement in flexion-extension. ${ }^{6}$ Thus indirect reduction with an ulna osteotomy was performed to help maintain reduction and improve function. ${ }^{7}$ With the current understanding of the importance of annular ligament in stability of the elbow, newer techniques aim at open reduction of the radial head with annular ligament reconstruction. Multiple techniques harvesting grafts like triceps tendon, palmaris longus (same side), tensor fascia lata, extensor carpi radialis longus tendon or Burnei 
procedure have been described. ${ }^{8-10}$ Using each of these tissues is associated with its own complications. In our technique we have used the fascia of the extensor carpi radialis longus tendon for repair of the annular ligament in 3 cases of chronic Monteggia fracture-dislocation. Chronic Monteggia fracture is defined as dislocation of radial head $>4$ weeks after injury.

\section{CASE REPORT}

We performed our technique in three cases of chronic monteggia fractures. Case 1, was a 30-year-old male with a 3-month-old dislocation and non-union of ulna fracture. Case 2, was a 41-year-old male with a 6-month-old dislocation and non-union of ulna fracture. Case 3 , was a 45-year-old female with a 3-month-old dislocation with ulna fracture uniting. Surgical plan for cases 1 and 2 was first to fix the ulna fracture and then to asses radial head position. If dislocated, open reduction of the radial head was performed in all the cases. After reduction, stability of the radial head throughout elbow range of motion was assessed. If at any point radial head was found to be unstable, decision of annular ligament reconstruction was made. Surgical technique was as follows: patients were lying in supine position with the arm resting on a mayo's table. Using modified kocher's approach, the radial head was exposed. Radial head reduction was achieved and stability assessed. Since radial head was unstable, annular ligament reconstruction was done. The extensor carpi radialis longus (ECRL) tendon and sheath was exposed through the same incision. Proximal $8 \times 1 \mathrm{~cm}$ strip of the ECRL fascia was marked (Figure 1).

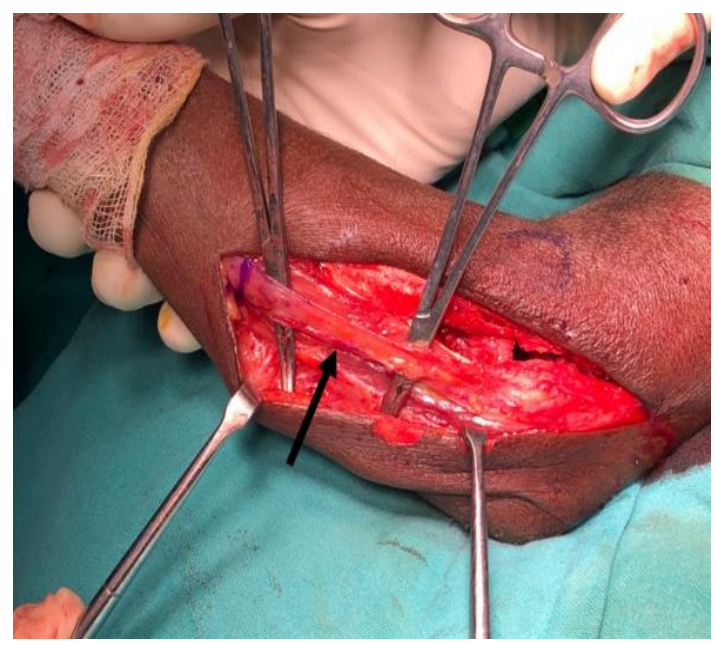

Figure 1: Harvesting strip of ECRL fascia.

Keeping the proximal end attached, the fascia was cut and separated. A modified krakow stitch was taken at the cut distal end using absorbable suture. This cut strip of fascia was then passed around the reduced radial head posterior to anterior and attached to the proximal end with absorbable suture (Figure 2, 3). After ascertaining the stability of reduction with elbow movements, closure was achieved in layers.

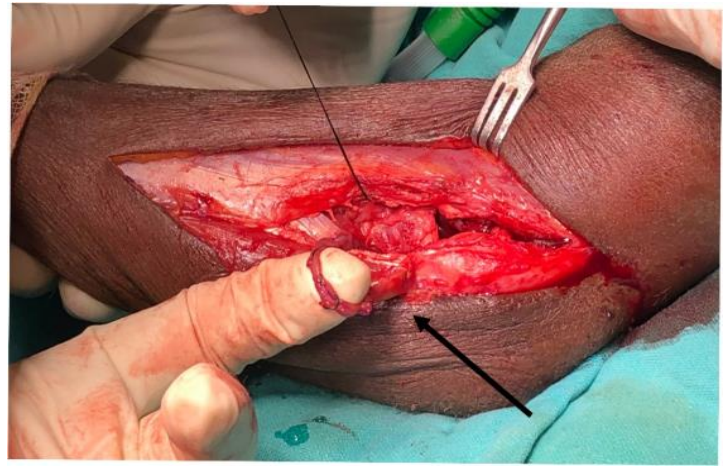

Figure 2: Passage of graft behind radial head.

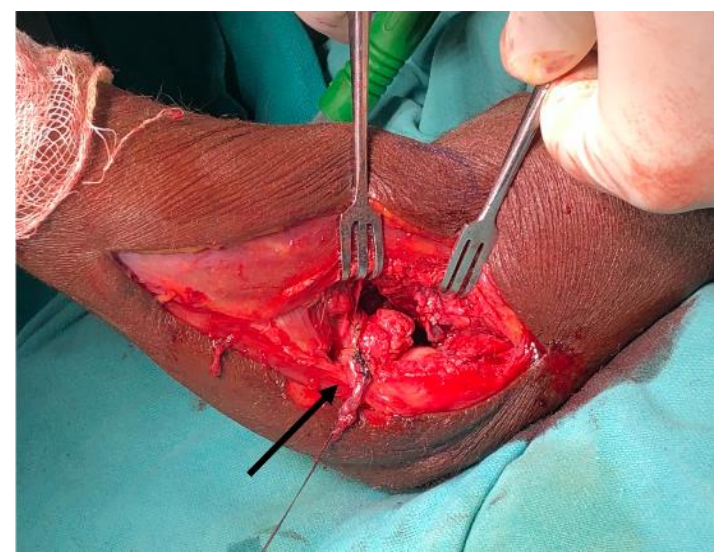

Figure 3: Graft sutured to proximal end with radial head reduced.

Post operatively patient was immobilized with a posterior above elbow slab with forearm in supination for 2 weeks. For the next 1 month, patient was given a dynamic elbow splint allowing flexion and extension with forearm fixed in supination. After this period active range of motion of the elbow, both flexion extension and pronation supination, was started.

\section{Outcome}

We had an average follow-up of 5 months. At 5 months follow-up, Case 1 had $0-130^{\circ}$ of flexion extension, full supination to mid pronation possible (Figure 4-6). At 6 months follow-up, Case 2 had $0-130^{\circ}$ of flexion-extension, full supination and mid pronation possible. At 4 months follow-up, Case 3 had $0-130^{\circ}$ of flexion-extension, full supination and full pronation possible.

$\mathrm{X}$-rays at final follow up in all 3 cases showed no evidence of radial head dislocation. Mean Visual Analogue Score for pain (0-10; 0 being no pain) was 2 at final follow up.

All 3 patients were satisfied with the surgery and were able to perform activities of daily living. No complications were noted. 


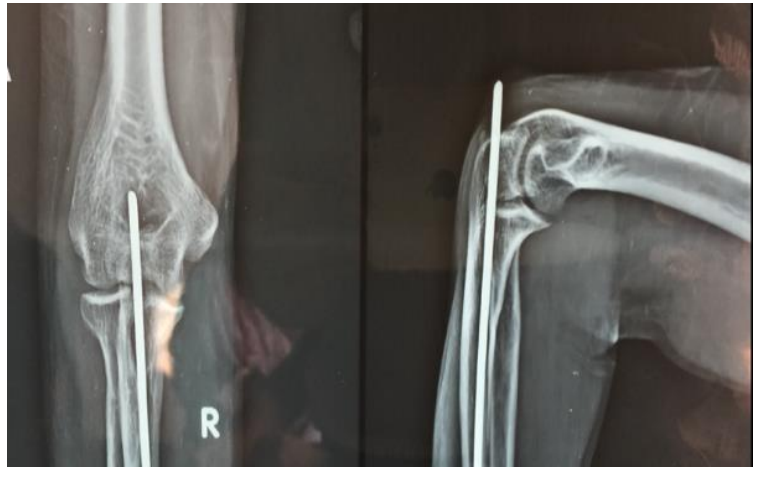

Figure 4: five month follow up X-ray showing reduced radial head of case 1 .

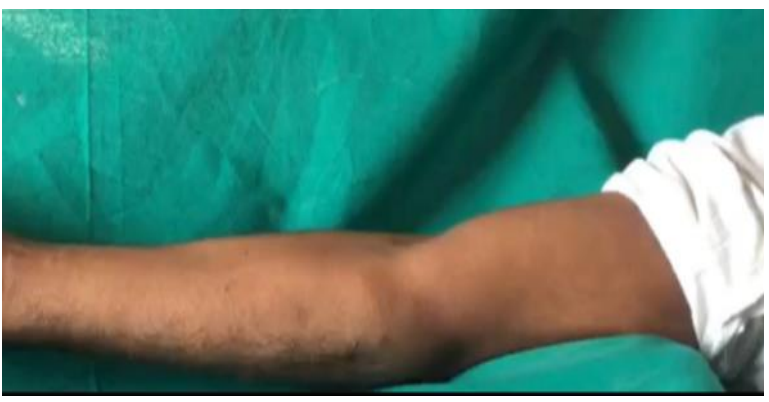

Figure 5: five month follow up Clinical photograph in full extension of case 1 .

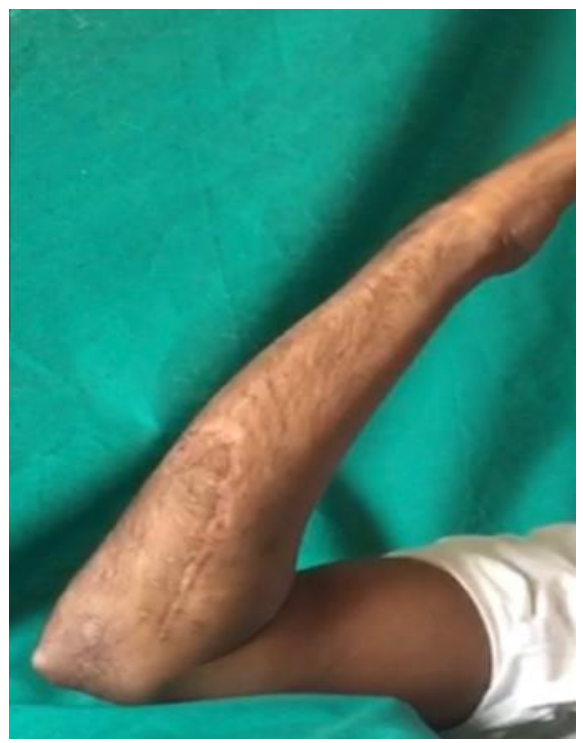

Figure 6: five month follow up clinical photograph in $130^{\circ}$ flexsion of case 1 .

\section{DISCUSSION}

Many surgeons advocate only use of ulna osteotomy to achieve indirect reduction of chronically dislocated radial head..$^{711,12}$ However in cases of radial head instability with normal ulnar alignment, reconstruction of annular ligament is advocated. ${ }^{13}$ In our report, all 3 patients had radial head instability inspite of normal ulnar alignment. It is important to understand that ulna osteotomy/realignment alone may not be sufficient to maintain radial head stability. Annular ligament is an important lateral stabiliser of the radial head, providing posterolateral stability. To achieve stability in a chronically dislocated radial head with normal forearm alignment, reconstruction of annular ligament is required.

Various grafts and techniques have been used to reconstruct the annular ligament. Burnei's procedure using extensor carpi radialis longus tendon has shown good postoperative flexion-extension and supination, with some restriction in pronation. ${ }^{10}$ Using a palmaris longus tendon graft and a suture anchor, Wang et al reported an average flexion of $134.2^{\circ}$, average supination of $86.4^{\circ}$ and average pronation of $85.8^{\circ}$ at last follow up..$^{9}$ Using a central strip of the triceps fascia, in a series of 9 patients, Bell Tawse reported full extension and flexion in 6 patients with slight restriction in pronation in 2 patients and loss of pronation in 1 patient. $^{8}$ Pari used a peroneal tendon allograft for reconstruction. They fixed the graft by a modified BellTawse technique. At 2 year follow up patient had $130^{\circ}$ flexion, $85^{\circ}$ supination and $5^{\circ}$ pronation. ${ }^{14}$ In our report, we reported an average flexion of $130^{\circ}$ and full supination in all 3 cases. 2 patients achieved mid pronation and 1 achieved full pronation. Our technique yielded results comparable to other techniques and grafts that have been used, with multiple other advantages.

Bell Tawse technique uses the triceps fascia requiring a longer incision. The palmaris fascia graft requires a separate incision for harvesting the graft. It also requires utilisation of suture anchor for the reconstruction. ${ }^{9}$ Allografts possess the risk of disease transmission. Canton et al have used the extensor carpi radialis longus tendon to reconstruct the annular ligament. ${ }^{15}$ In our technique we are able to reconstruct the annular ligament through a single incision, requiring no hardware, using only the fascia overlying the extensor carpi radialis longus tendon.

Anatomical reconstruction of the annular ligament requires drilling of the ulna and an extra incision over the ulna. Our technique anchors the radial head to the lateral condyle and common extensor origin, thus supplementing the lateral collateral ligament complex. Even though not anatomical, it has shown similar results as compared to anatomical reconstructions like the Bell Tawse technique. By performing such a reconstruction, we also avoid the risk of damage to the ulna and proximal radioulnar joint, requiring no additional incision or hardware. Similar nonanatomic reconstruction has been used successfully as described by burnei. ${ }^{10} \mathrm{Kim}$ et al reported that annular ligament reconstruction may cause loss of pronation, notching of radial head, anterior or posterior subluxation, heterotopic ossification or wound infection. However, no functional disability was noted. ${ }^{16}$ Do Boeck reported 1 case of partial resorbtion of radial neck after using triceps tendon graft. ${ }^{17}$ this may be due to excessive tension of the reconstructed annular ligament. We reported no complications in our series. 


\section{CONCLUSION}

In conclusion, our novel technique of annular ligament reconstruction using the fascia overlying extensor carpi radialis longus tendon is simple, cost effective, requiring no hardware with excellent functional outcomes.

Funding: No funding sources

Conflict of interest: None declared

Ethical approval: Not required

\section{REFERENCES}

1. Gray H, In: Leatherette B, Warren H L, eds. Anatomy of the human body. 20th ed. Philadelphia: Lea and Febiger; 1918.

2. Zhang X, Gan RZ. Dynamic properties of human stapedial annular ligament measured with frequencytemperature superposition. J Biomech Eng. 2014;136(8): 0810041-7.

3. Cohen MS, Hastings H. Rotatory Instability of the Elbow. The Anatomy and Role of the Lateral Stabilizers. J Bone Joint Surg Am. 1997;79:225-33.

4. Dunning CE, Zarzour ZD, Patterson SD, Johnson JA, King GJ. Ligamentous stabilizers against posterolateral rotatory instability of the elbow. J Bone Joint Surg Am. 2001;83(12):1823-8.

5. Søjbjerg J, Ovesen J, Gundorf C. The stability of the elbow following excision of the radial head and transection of the annular ligament. Arch Orthop Trauma Surg. 1987;106(4):248-50.

6. Bengard MJ, Calfee RP, Steffen JA, Goldfarb CA. Intermediate-term to long-term outcome of surgically and nonsurgically treated congenital, isolated radial head dislocation. J Hand Surg Am. 2012;37(12):2495-501.

7. Eygendaal D, Hillen RJ. Open reduction and corrective ulnar osteotomy for missed radial head dislocations in children. Strategies Trauma Limb Reconstr. 2007;2(1):31-4.

8. Tawse AJB, The treatment of malunited anterior Monteggia fractures in children. J Bone Joint Surg Br. 1965;47(4):718-23.
9. Wang J, Jiang L, He A, Wang DR, Jhu J, Daun RS, et al. Annular ligament reconstruction by suture anchor for treatment of radial head dislocation in children. BMC Musculoskelet Disord. 2015;16:181.

10. Ghinea CA, Gavriliu S, Georgescu I, et al. Burnei's technique in the treatment of radial head displacement; innovative surgery. Study on two cases. J Med Life. 2013;6(1):26-33.

11. Lädermann A, Ceroni D, Lefèvre Y, De Rosa V, De Coulon G, Kaelin A. Surgical treatment of missed Monteggia lesions in children. J Child Orthop. 2007;1(4):237-42.

12. Delpont M, Jouve JL, Gauzy SJ, Louhaem D, Viale $\mathrm{R}$, Bollini G, et al. Proximal ulnar osteotomy in the treatment of neglected childhood Monteggia lesion. Orthop Traumatol Surg Res. 2014;100(7):803-7.

13. Marinello PG, Wagner T, Styron J, Maschke S, Evans PJ. Annular Ligament Reconstruction with Triceps Autograft for Chronic Radial Head Instability. Tech Hand Up Extrem Surg. 2016;20(1):21-5.

14. Pari C, Puzzo A, Paderni S, Belluati A. Annular ligament repair using allograft for the treatment of chronic radial head dislocation: a case report. Acta Bio-medica: Atenei Parmensis. 2018;90(1):154-7.

15. Canton G, Hoxhaj B, Fattori R, Murena L. Annular ligament reconstruction in chronic Monteggia fracture-dislocations in the adult population: indications and surgical technique. Musculoskeletal Surger. 2018;102(S1):93-102.

16. Kim HT, Park BG, Suh JT, Yoo CI. Chronic radial head dislocation in children, Part 2: results of open treatment and factors affecting final outcome. $\mathrm{J}$ Pediatr Orthop. 2002;22(5):591-7.

17. De Boeck H. Radial neck osteolysis after annular ligament reconstruction. A case report. Clin Orthop Relat Res. 1997;(342):94-8.

Cite this article as: Maniar A, Kakatkar S. A novel technique of annular ligament reconstruction using extensor carpi radialis longus tendon fascia: a report of 3 cases. Int J Res Orthop 2021;7:679-82. 